\title{
Engineering Review Food Extrusion Technology and Its Applications
}

\author{
Kehinde Adedeji Adekola \\ Institute of Agricultural Products Processing and Storage, College of Biological and Agricultural Engineering, Jilin University, \\ Changchun 130022, China
}

\begin{abstract}
An extensive technical review of studies on food extrusion processes which involves forcing mixed food ingredients through a die to produce food snacks has been carried out in this paper. This technical review includes some historical development, food extruder types, extrusion principles and applications, flow simulation and heat transfer modeling in extruders, process parameters and product quality, extruder die and extrudate expansion among others. The research and application of extrusion in food industry was mainly based on the adaptation of plastic extrusion technology which has been in existence for over hundred years. Studies show that twin-screw extruder are more efficient than single-screw extruders because of better mixing and better handling of different combinations of food ingredients. A thorough knowledge of the flow and heat behavior inside an extruder provide an insight into the mechanism of mixing and facilitates estimation of RTD, flow rate, pressure drop, heat transfer mechanism and power consumption. Until recently, very little work has been published on the mechanism of material flow and energy transfer in intermeshing co-rotating extruder mainly due to the complexity of the geometry and the flow behavior. A more recent approach to research in modeling of food extrusion is the 2D or 3D flow modeling using finite element computer package. This research area is gaining recognition in modeling different sections of food extruder. This work also points out some of the achievements and shortcomings of the reviewed works and where necessary, possible solutions are suggested. Areas needing further research have been highlighted. This study will reveal that understanding and application of extrusion technology in developing countries of Asia and Africa are still far from being satisfactory and this work would serve as a good reference material for researchers and operators in food extrusion technology.
\end{abstract}

Key words: Food extrusion, technical review, extruders, research, applications.

\section{Introduction}

Food extrusion can be defined as a process of mixing, homogenizing and shaping low moisture food materials and more recently high moisture food materials into intermediate or finished products by forcing them through a specially designed die. The word "extrudate" originates from the Latin word "ex" (out) and "trudere" (to thrust) [1].

Food extrusion is a modern high temperature short time (HTST) cooking process with several other unit operations such as conveying, kneading, heating, mixing and forming in a single unit. Extrusion food processing is widely used to restructure starch and

Corresponding author: Kehinde Adedeji Adekola, doctor, research fields: food extrusion technology and oil-seeds processing. protein based food materials to manufacture a variety of ready to eat (RTE) breakfast cereals: paste, bread substitutes and pet foods [2].

This extrusion process normally involves applications of intensive energy to food ingredients at a pressure within a short period of time to form continuous viscous dough. The laminar flow within the channels on the extrusion screw and extruder die aligns the molecules in the direction of flow to create the crunchy or chewy texture in fabricated food $[3,4]$.

Extrusion cooking has indeed revolutionized the food industry as it has obvious advantages over conventional food processes. The working time at high temperature is a matter of seconds, which has favorable effects in maintaining the properties of the ingredients and active substances while giving high 
rate of destruction of harmful microorganisms and leading to the end products of long shelf life on account of their low process moisture content. Continuous extrusion cooking has economic advantages because of replacing many batch processes and handling almost entirely with the final moisture content, thus avoiding the necessity to evaporate large quantity of water [5].

Functionally, a food extruder can be divided into six sections as shown in Fig. 1 below [6].

(a) Power source, which supplies the energy needed to cause the rotation of the screw, feeder and other moving parts of the extruder;

(b) The feed section, which meters the feed materials and ensures that feed materials are received and conveyed to the screw;

(c) The shearing/compression section in which the materials are thoroughly worked into viscous dough, partially cooked and elevated in temperature and pressure;

(d) The metering section in which dough is further cooked and starch granules may be broken down due to higher shear forces. The metering section continuously feeds the die with materials at uniform pressure;

(e) The die section allows rapid expansion "puffing" of the dough into various shapes and sizes depending on the configuration of the die section; (f) The cutting section cuts the extrudates into required uniform sizes. The cutting speed can be adjusted to suit production requirements in terms of length and shape of extrudates.

Generally, food extruder can be broadly classified as single-screw and twin-screw extruders. Raw materials with a high coefficient of friction such as maize grits, rice cones or even whole grain develop good drag flow in single-screw extruders (Frame, 1993). For this reason, they are widely used for extruding snacks and breakfast cereals. Twin-screw extruders are classified into co-rotating and counter-rotating depending on the relative movement of one screw to the other. The mixing is limited to inside the channel and they can provide very short residence time distribution (RTD) [6].

Co-rotating extruders offer better conveying, mixing and narrower RTD than single screw extruders [6]. In comparison with counter-rotating extruder, co-rotating extruder can be operated at a much higher speeds thus providing higher shear rate greater throughputs and better mixing.

The die is a major component of the extruder. The die area is the section of the extruder that occurs after the food material leaves the extruder screw. The die has been described as the transitional piece which changes the direction of the dough flow from horizontal (as it leaves the extrusion screw) to the

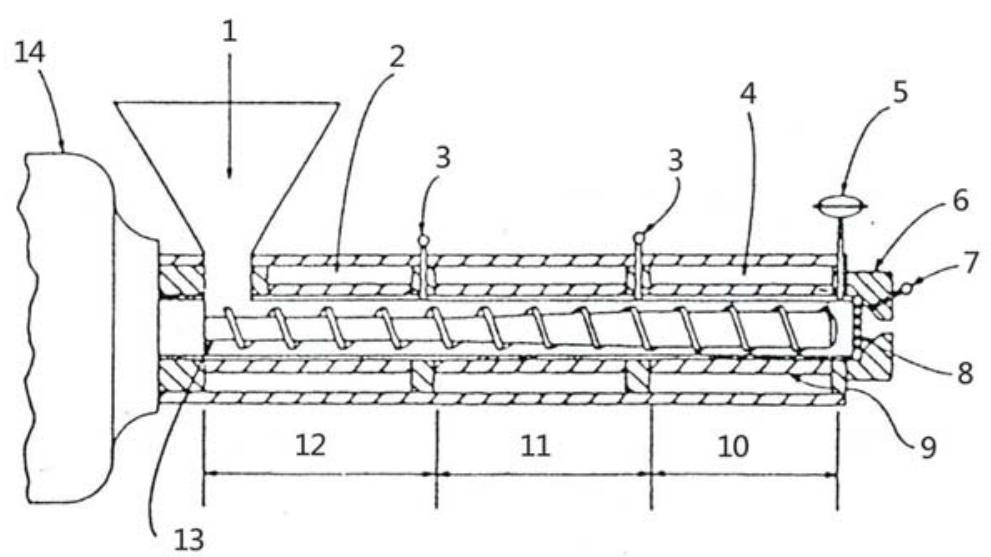

Fig. 1 Mechanical sections of a single-screw food extruder.

1. Feed hopper; 2. Cooling water jacket; 3. Thermocouples; 4. Barrel steam jacket; 5. Pressure transducer; 6. Die; 7. Discharge thermocouple; 8.Breaker plate; 9. Barrel with hardened liner; 10. Metering section; 11. Compression section; 12 . Feed section; 13. Screw with increasing root diameter; 14 . Drive, gear reducer and thrust bearing. 
vertical (as it passes through the die). The die normally consists of three parts, which are the transition, distribution and die plates sections. When the dough leaves the die, the temperature and pressure drop abruptly and the product expands. A proper understanding of the material properties and the nature of flow in the extruder die are essential in controlling the extruder performance and extrudate quality [7].

Studies have shown that the discussed technology is well developed in Western Europe and America. This technology has started and undergone a lot of improvement in these regions in the last half a century [6]. A lot of improvements have been made in machine development, process optimization and variety of extrudates. Research works are still going on. Many of the countries in Africa and Asia are yet to fully know the potentials of the technology. Some of the reasons adduced for this, including lack of access to information on the technology, inadequate financial resources to pursue meaningful research into the area, lack of experts in the area of extrusion technology and different eating habits of the people in these countries. Another possibility may be the unwillingness of the technology developer to transfer the technology to developing countries.

\section{Food Extruders and Food Extrusion}

The history and development of extrusion cooking is closely linked with the development of extrusion in plastic industry. The earliest recorded industrial extruder is a machine invented by Joseph Bramah. The first patent on an extrusion machine using an Archimedean screw was granted to Gray [9] in England and Royle [10] in the United States. Fig. 2 shows the oldest continuous twin-screw described in 1881 which is a tangential counter-rotating machine [11]. It is used for coloring and shaping chewing gum. It was in 1946 that single-screw extruders were used commercially for the extrusion cooking and expansion of corn snacks [5]. In the seventies, the use of twin-screw extruders became predominant. This trend has been continuing up to date.

The first reported work on simulation and modeling of twin-screw extruder was done by Yacu in 1984 [12]. He proposed comprehensive global model for some functional zones of the extruder (solid conveying, melt pumping and melt shearing zones). Extruders are in a wide variety of shapes, sizes and operational procedures. Extruders can be classified in a variety of ways. Some are based on (a) method of operation; (b) functional characteristics related to the type of products produced; (c) thermodynamic considerations and (d) moisture content of the feed ingredient.

In single-screw extruder the rotating extrusion screw in a tightly fitting barrel conveys, heats and works food ingredients into continuous plasticized mass. The screw has three sections: (i) feed ii) transition (iii) metering. The feed section receives and

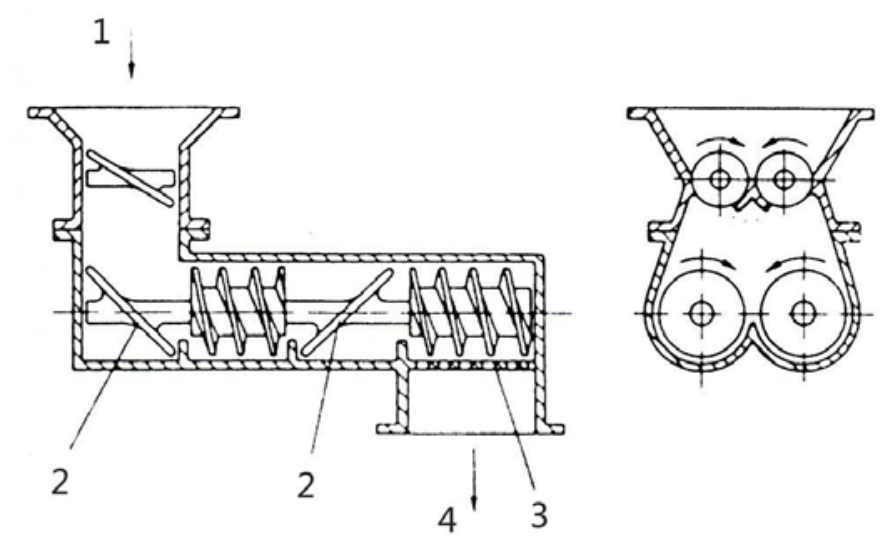

Fig. 2 Twin screw counter-rotating screw mixer with blades, invented by Paul Pfeiderer. 1. Product feed; 2. Mixing blades; 3. Die plate; 4 . Mixed product discharge. 
conveys the feed materials into the extruder. The transition section causes a rapid increase in temperature and compression ratio of the food material. When all these three flows (drag, cross channel and pressure flow) in single-screw are combined, the net flow is material flow out of the extruder die, which has experienced a certain amount of mixing [8].

Single-screw extruders can also be classified based on the screw-barrel configuration (Fig. 3). It has been shown that appropriate screw design is dependent on the flow properties of the material to be extruded and the amount of pressure that has to be developed by the screw [14].

Design of the die, the melt flow properties of the polymer, the throughput rate and the melt temperature determine the amount of pressure that has to be developed by the screw. An important mechanical consideration for screw design is the torsion strength i.e. the ability to transmit the torque to turn the screw [15]. A review of the operating characteristics of single-screw extruder is given below (Table 1).

In summary, operation of a single-screw is dependent on the screw speed, degree of fullness of

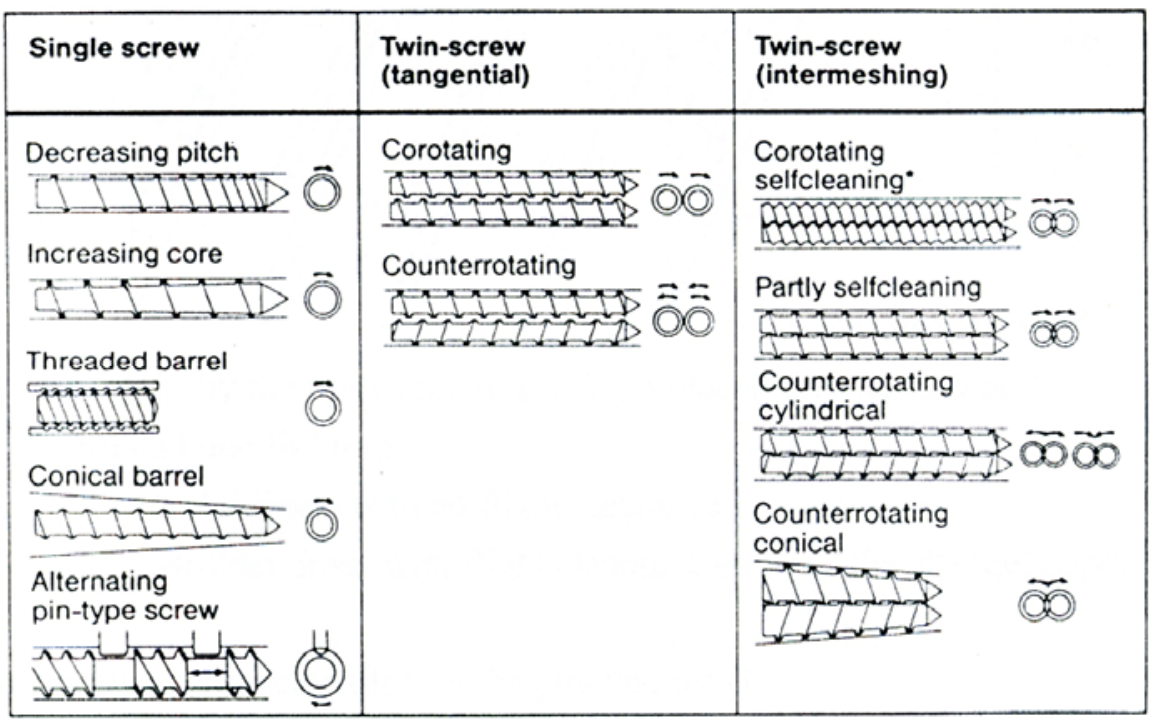

Fig. 3 Screw-barrel configurations for food extruders.

Table 1 Some operating characteristics of single-screw extruder.

\begin{tabular}{|c|c|c|c|}
\hline Operating variable & Low shear forming extruder & Moderate shear cooking extruder & High shear cooking extruder \\
\hline 1. Feed moisture, \% w.b. & $25-25$ & $20-30$ & $12-20$ \\
\hline $\begin{array}{l}\text { 2. Maximum product } \\
\text { temperature, }{ }^{\circ} \mathrm{C}\end{array}$ & $50-80$ & $125-175$ & $150-200$ \\
\hline 3. Length/Diameter & $5-8$ & $10-20$ & $4-12$ \\
\hline 4. Diameter/Height & $3.0-4.5$ & $5-10$ & $7-12$ \\
\hline 5. Compression ratio & $1: 1$ & 2-3:1 & 3-5:1 \\
\hline 6. Screw speed, $\omega, s^{-1}$ & $3-4$ & $10-25$ & $30-45$ \\
\hline 7. Shear rate, $\gamma, s^{-1}$ & $5-10$ & $20-100$ & $100-180$ \\
\hline $\begin{array}{l}\text { 8. Net mechanical energy } \\
\text { input, } \mathrm{KJ} / \mathrm{kg}\end{array}$ & $0.03-0.04$ & $0.02-0.04$ & $0.10-0.14$ \\
\hline $\begin{array}{l}\text { 9. Net energy input to } \\
\text { product, } \mathrm{KJ} / \mathrm{Kg}\end{array}$ & $0.02-0.03$ & $0.02-0.04$ & $0.07-0.14$ \\
\hline 10. Product types & $\begin{array}{l}\text { Macaroni, RTE cereal pellets, } \\
\text { second generation snacks. }\end{array}$ & $\begin{array}{l}\text { Soft moist pet food, pre-gelatinized } \\
\text { starch, drink and soup bases, textured } \\
\text { plant protein, RTE breakfast cereals. }\end{array}$ & $\begin{array}{l}\text { Puffed starch dry pet foods, } \\
\text { modified starch. }\end{array}$ \\
\hline
\end{tabular}


screw, slip at the barrel wall, melt characteristics and most importantly pressure required by the die. Barrel wall temperature and the presence of barrel wall groove control the slip at the wall while melt characteristic is influenced by moisture content and temperature.

A twin-screw extruder consists of two parallel screws turning towards the interior of a barrel having a section in form of a figure eight. Twin-screw extruders are divided into co-rotating and counter-rotating depending on the relative direction of rotation of the screw. Co-rotating extruders have the screw turning in the same direction while counter-rotating extruders have the screws turning in the opposite direction (Fig. 4)

The most common form of co-rotating twin-screw is the fully intermeshing self-wiping style. The product can not rotate within the screw as its rotation is impeded by the flight of the other screw. Co-rotating extruders offer better conveying function, narrower residence time distribution and can readily transport sticky food ingredients better than single screw ones [16]. In food processing, intermeshing, self-wiping co-rotating twin screw extruder is the most popular because of its flexibility to produce a wide variety of food products and its higher capacity.

Screw design in food extruder is a study area that has received attention for several decades and it is a very important component of an extruder [17-21]. Fig. 5 shows different twin-screw configurations for food extruders.

A minor change in the geometry of the screw can affect the entire extrusion process. The design consideration for extruder screw are: (i) the motor size; (ii) the volumetric flow requirement; (iii) degree of fullness; (iv) compromise between pumping efficiency and rheology of the material; (v) pressure and flow distribution at the entrance to the die; (vi) degree of shear/mixing required; (vii) strength and wear characteristics; (viii) ease of operational flexibility and ix) cost.

\section{Food Extruder Flow Modeling}

In food extrusion field, application of models to the processes has begun less than three decades ago [22]. Modeling food extruders depends mainly on developments in plastic extrusion. However, it is important to appreciate the similarities and differences in feed materials.

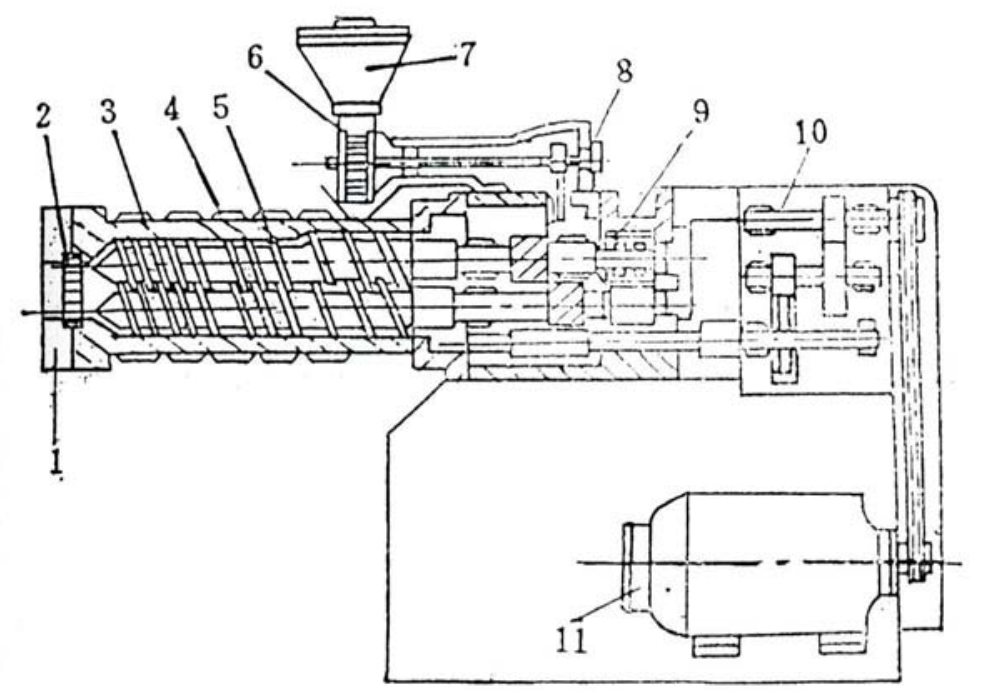

Fig. 4 Twin-screw extruder structural diagram.

1. Die housing; 2.Die plate; 3. Extruder barrel; 4.Heater; 5.Twin screw; 6. Feed gage; 7. Hopper; 8. Feed metering device; 9. Bearing; 10. Gear box; 11. Electric motor. 


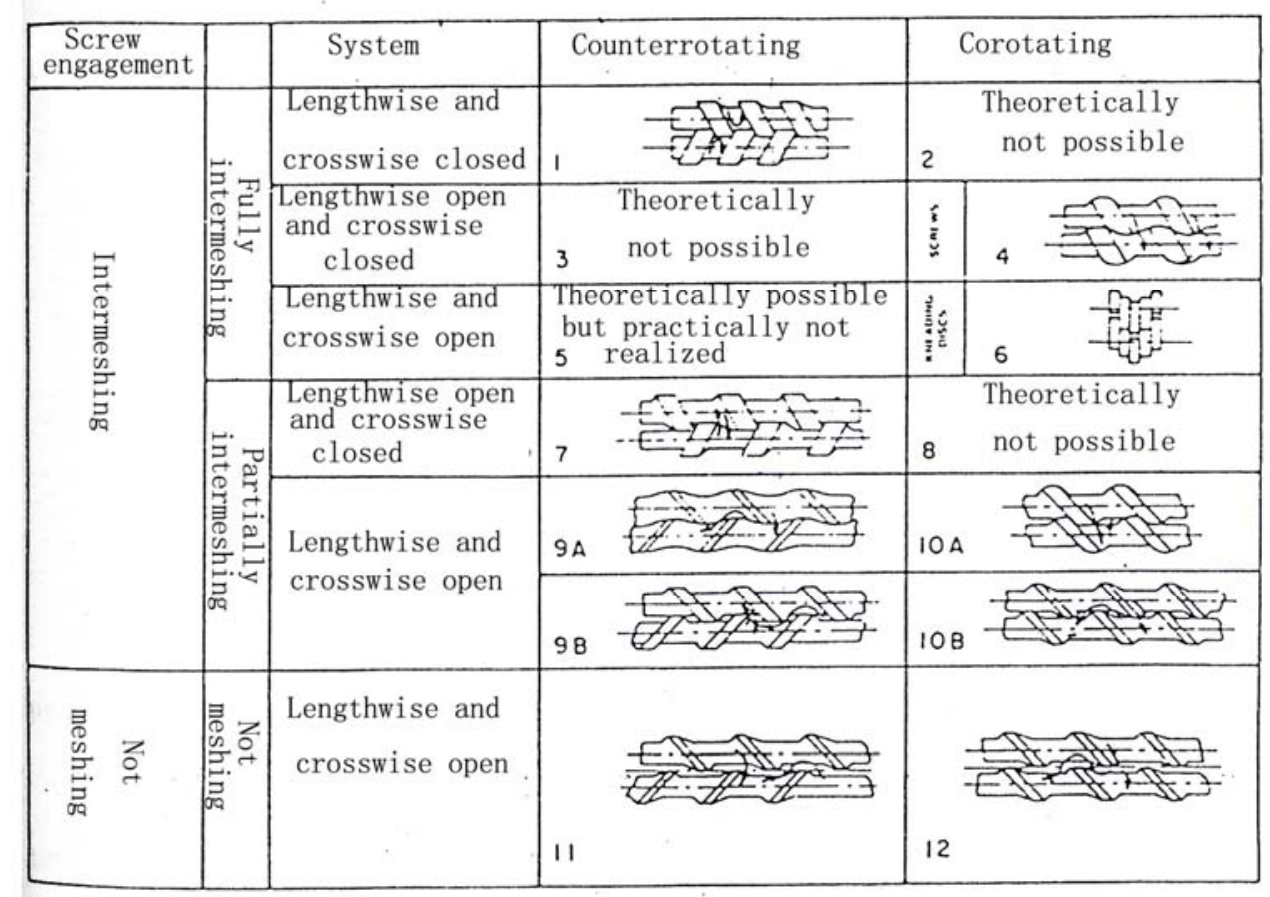

Fig. 5 Twin-screw extruder configurations.

Plastics are more homogeneous in nature that can be characterized chemically and physically. On the other hand, food extrusion uses a variety of food ingredients as feed materials. These materials are biopolymers of starch or protein, which varies in their source, age, prior treatment and thus cause extensive alteration in the chemical and physical nature of food extrudes. Modeling in food extrusion is much more complex process than plastic extrusion.

Most studies concerning modeling in food extrusion can be classified into six as black-box modeling, comprehensive modeling, response surface modeling (RSM), fuzzy modeling, residence time distribution (RTD) curves and finite element approach. All these methods have their advantages and limitations. Depending on the requirements of the modeling/analysis any of these methods are applicable [6]. The major limitations of black-box modeling are that resulting equations can only be used within the experimental data range and there is no explanation about the phenomena occurring inside the extruder. So, it can not solve the problem of scale up. Comprehensive modeling is limited by the preliminary assumptions that such a model allows numerical simulation of other geometries, experimental data and products. The major limitations of RSM are the dependency of the results on the presupposed model equation and predefined range of variables. No information of other important process variables was included in the experimental design [23].

Until recently, very little work has been published on the mechanism of material flow and energy transfer in intermeshing co-rotating extruder mainly due to the complexity of the geometry and the flow behavior. Most of the reported works treated melt flow in twin screw as similar to single screw extruder which is a combination of drag and pressure flows assuming a Newtonian and isothermal condition [24]. An improvement was made by Booy [25] who added a third flow element due to pushing action of the second screw in the intermeshing region.

A thorough knowledge of the flow behavior inside an extruder provides an insight into the mechanism of mixing and facilitates estimation of RTD, flow rate, pressure drop and power consumption. The flow pattern may be derived from theoretical velocity 
profile for food mix in the extruder for Newtonian and Non-Newtonian fluids under isothermal and non-isothermal conditions for single-screw extruder [26]. The same approach had also been used for twin screw extruder with intermeshing, counter-rotating screws [27] to determine material flow pattern. An alternative method of using RTD to model flow pattern of food mixture in the extruder has also been thoroughly examined [28].

A simplified basic model for co-rotating twin screw extruder with deep screw channel has been developed [29] and it was based on solving thermal balance and Stokes equation. The model divided twin screw extruder into four functional sections (conveying, melt pumping, shearing and die). The model described the evolution of temperature only in the conveying section and isothermicity was assumed in other three sections. The model also described isothermal evolution of pressure in the melt pumping and the reverse screw with a Newtonian viscosity.

Similar to single screw modeling, the equation of flow assumed that the screws were stationary with the barrel slipping over them. Therefore, kinematics theory imposes [30] that the other screw must turn around the stationary screw without turning around its own axis. In the conveying section, the product is still in its powder form and since twin-screw extruders are mostly starved-fed, it was computed that the filling rate of screw channels is low. This explains why there is no pressure development, so only heat transfer is of interest in the conveying section.

A more recent approach to research in modeling of food extrusion is the 3D flow modeling using finite element computer package. Works on either 2D or 3D finite element analysis for food extrusion in literature are limited. The application of the method to extruder die is unknown. As a result, a recent work was carried out on 2D flow simulation in twin-screw food extruder die [6, 7, 13]. In all the published studies reviewed [28, 31-35] and which some are highlighted in this paper, flow pattern modeling was restricted to various sections of the extruder screw (compression, melting and metering sections) with virtually no mention of the pattern in extruder die. The knowledge of flow pattern in the screw could serve as the basis for understanding the flow pattern within the die which is essential for extruder die design [4].

It is very important to be able to predict the effects of processing and material parameters on product temperature because of sensitivity of food raw materials to over or under-treatment. Inappropriate heat treatment of food materials can result in low nutritional value with unacceptable organoleptic characteristics. Knowledge of the heat transfer encountered in food extrusion is essential for the scale-up and design of food extruder and temperature control systems.

Most of the early models on melting and heat transfer in extruder were mainly on the metering section in single screw extruders under the assumption of Newtonian and isothermal flow condition [36]. In actual production, food materials exhibit a non-Newtonian rheological behavior during extrusion.

Several authors [6, 12, 13, 37-40] have produced useful models for understanding the extrusion of most food materials, which exhibited a non-Newtonian rheological behavior. A numerical analysis method was used to solve the differential equation for fully developed velocity and temperature profiles for single-screw extrusion of power-law fluid [41]. Finite-difference technique was also used to solve the equation of flow of non-Newtonian fluid [42]. He assumed that temperature did not change along the channel. Considering the geometry of die, the finite element analysis can form the basis for studies of heat transfer in die.

\section{Food Extruder Heat Transfer Modeling}

It is very important to be able to predict the effects of processing and material parameters on product temperature because of sensitiveness of food raw material to over or under-treatment. Inappropriate heat 
treatment of food material can result in low nutritional value with unacceptable organoleptic characteristics.

Most of the early models on melting and heat transfer in extruder were mainly on the metering section in single-screw extruders [43, 44] under the assumption of Newtonian and isothermal flow condition [36, 45]. In actual production, food materials exhibit a non-Newtonian rheological behavior during extrusion. For non-Newtonian rheological behavior, a numerical analysis method was used to solve the differential equations for fully developed velocity and temperature profiles for single screw extrusion of power-law fluid [41]. Finite-difference technique was also used to solve the equation of flow of non-Newtonian fluid [42]. He assumed that temperature did not change along the channel. Considering the geometry of die, the finite element analysis can form the basis for studies of heat transfer in die [7].

Work has been done on dimensionless heat transfer coefficient for non-Newtonian flow [46-48] with viscous dissipation [12, 49, 50]. An analysis of Graetz-Nusselt problem was done and developed a theoretical model to determine the effects of material properties, geometry and operating conditions on heat transfer coefficient in single-screw food extruder for both cooling and heating at constant barrel temperature [50].

Heat transfer coefficient is essential for food extrusion modeling, scale up and design of food extruder. The theory of heat penetration was developed in 1953 [48]. This theory considered that after the flight of the rotating screw has wiped a certain area on the inner barrel surface, a fresh layer of melts becomes attached to the same region and remains there for approximately one revolution in twin-screw extruder. He simulated three sections of the extruder (solid conveying, melt pumping and melt shearing zones) in the same region and remained there for approximately one revolution. For this model, the energy equation containing conduction and convection term is given below:

$$
\begin{aligned}
& \rho C_{p} \frac{\partial T}{\partial t}=\lambda\left(\frac{\partial^{2} T}{\partial x^{2}}+\frac{\partial^{2} T}{\partial y^{2}}+\frac{\partial^{2} T}{\partial z^{2}}\right)+ \\
& \rho C_{p}\left(v_{x} \frac{\partial T}{\partial x}+v_{y} \frac{\partial T}{\partial y}+v_{z} \frac{\partial T}{\partial z}\right)+q
\end{aligned}
$$

where, $C_{p}$ is the heat capacity $(\mathrm{J} /(\mathrm{kg} \cdot \mathrm{K})) ; \quad \rho$ is the density $\left(\mathrm{kg} / \mathrm{m}^{3}\right) ; T$ is the temperature $(\mathrm{K}) ; \quad v$ is the velocity vector, components $v_{x}, v_{y}, v_{z}(\mathrm{~m} / \mathrm{s}), \lambda$ is the thermal conductivity $(\mathrm{J} /(\mathrm{s} \cdot \mathrm{m} \cdot \mathrm{K})), q$ is the heat flux vector, components $q_{x}, q_{y}, q_{z}\left(\mathrm{~J} /\left(\mathrm{m}^{2} \cdot \mathrm{s}\right)\right) ; x, y, z$ are coordinate indices.

Using Pollhausen momentum method for one dimension, the temperature distribution is:

$$
\frac{T_{y}-T_{0}}{T_{b}-T_{0}}=\left(1-\frac{y}{z}\right)^{2}
$$

where, $z$ is the total penetration depth of the heat, $y$ is an ordinate between the wall $(y=0)$ and the maximum temperature layer dimension $(y=z), T_{b}$ is the barrel temperature, $T_{0}$ is the bulk product temperature, and $T_{y}$ is the temperature at location $\mathrm{y}$.

If the viscous dissipation in the boundary layer is neglected, the heating of a small boundary layer from $T_{0}$ to $T_{1}$ can be described by the Fourier equation:

$$
\frac{d T}{d t}=a \frac{d^{2} T}{d y^{2}}
$$

where, $a$ is the thermal diffusivity $\left(\mathrm{m}^{2} / \mathrm{s}\right)$; $t$ is the time (s).

Using the Pollhausen approximation, the penetration depth $z$ is:

$$
z=2 \sqrt{3 a t}
$$

The heat flux transferred per unit time into the boundary layer is:

$$
\Phi_{w}^{\prime \prime}=\rho C_{p}\left(T_{1}-T_{0}\right) \sqrt{\left(\frac{a}{3 t}\right)}
$$

The resulting heat transfer coefficient, $\alpha$ is: 


$$
\alpha_{z}=\rho C_{p} \sqrt{\left(\frac{a}{3 t}\right)}
$$

From the equation above, it is evident that the heat transfer coefficient and the resulting heat flux per unit time and area decreases with the penetration of the heat. Therefore, it is important to find the average transferred heat and average heat transfer coefficient, which are presented below respectively:

$$
\Phi_{w_{\text {average }}^{\prime \prime}}^{\prime}=\sqrt{\left(\frac{4}{3 \lambda \rho C_{p} N}\right)}\left(T_{1}-T_{0}\right)
$$

and

$$
\alpha_{\text {verage }}=\sqrt{\left(\frac{4}{3 \lambda \rho C_{p} N}\right)}
$$

where, $\Phi_{w}^{\prime \prime}$ is the heat flux per square meter ( $\mathrm{J}$ $\left./ \mathrm{m}^{2}\right) ; \lambda$ is the thermal conductivity $(\mathrm{J}(\mathrm{s} \cdot \mathrm{m} \cdot \mathrm{K})) ; N$ is the screw speed $(\mathrm{r} / \mathrm{s})$.

For the reason that heat penetration in an extruder is considered as non-stationary semi-infinite, the flow is generally referred to as Leveque flow. The velocity gradient is constant and is theoretically written as:

$$
v_{x}=\dot{\gamma} y
$$

where, $\dot{\gamma}$ is the shear rate $\left(\mathrm{s}^{-1}\right)$.

For $\mathrm{x}=0$, the flow touches the wall at a uniform temperature. The heat balance is:

$$
\dot{\gamma y} \frac{\delta T}{\delta x}=a \frac{\delta^{2} T}{\delta y^{2}}
$$

boundary conditions:

$$
\begin{aligned}
& x<0, T=T_{0} \\
& x>0, y \rightarrow \infty, T=T_{0} \\
& x>0, y=0, T=T_{1}
\end{aligned}
$$

With these conditions, the Pollhausen approximation gives the value of penetration depth to be:

$$
z=\left(\frac{36 a x}{\dot{\gamma}}\right)^{\frac{1}{3}}
$$

the heat flux is:

$$
\Phi_{w}^{\prime \prime}=2 \lambda\left(\frac{36 a x}{\dot{\gamma}}\right)^{-\frac{1}{3}}\left(T_{1}-T_{0}\right)
$$

the heat transfer coefficient is :

$$
\alpha_{z}=2 \lambda\left(\frac{36 a x}{\dot{\gamma}}\right)^{-\frac{1}{3}}
$$

It should be noted that the above calculations are only applicable to a short time heat penetration with almost linear velocity profile.

Another study [51] developed heat transfer model for twin-screw extruder. He simulated three sections of the extruder (solid conveying, melt pumping and melt shearing zones). The model was based on the following assumptions: (i) the food melt rheology is non-Newtonian and non-isothermal viscosity model, taking into account the effect of moisture and fat content; (ii) steady-state behavior and uniform conditions; (iii) the melt flow is highly viscous and in the laminar flow regime; (iv) gravity effects are negligible; (v) heat losses to the screw shaft are neglected; (vi) only heat in the axial direction is considered.

For the solid conveying section of the model, the heat balance across an element normal to the axial direction is:

$$
\begin{gathered}
Q_{m} C_{p s} T+F U_{s} A\left(T_{b}-T\right) \delta X= \\
Q_{m} C_{p s}(T+d T)
\end{gathered}
$$

solving for $\mathrm{T}$ with the boundary condition at $\mathrm{X}=0, \mathrm{~T}$ $=T_{1}^{0}$

$$
T=T_{b}-\left(T_{b}-T_{1}^{0}\right) \exp \left(\frac{-F U_{s} A X}{Q_{m} C_{p s}}\right)
$$

where, $Q_{m}$ is the feed rate $(\mathrm{kg} / \mathrm{s}) ; C_{p s}$ is the heat capacity of solid matter $(\mathrm{J} /(\mathrm{kg} \cdot \mathrm{K})) ; F$ is the degree of fill; $U$ is the relative velocity of barrel wall with respect to centerline of screw which equals to 
$\pi \mathrm{ND}(\mathrm{m} / \mathrm{s})$; subscript $\mathrm{s}$ is solid (powder); $A$ is the surface area $\left(\mathrm{m}^{2}\right) ; X$ is the axial distance $(\mathrm{m}) ; \delta$ is the flight clearance $(\mathrm{m}) ; T_{b}$ is the barrel temperature $(K)$. The values of $U_{s}$ are lower than the heat transfer coefficient predicted by the penetration theory. The reason for this is the existence of additional resistance to heat transfer between the solid particles.

In the melt pumping section, it was estimated that the energy converted to thermal heat by viscous dissipation per screw channel in one turn is the summation of the four situations in which energy was converted. Therefore, the total energy charge per channel per screw is

$$
Z_{p}=Z_{1}+Z_{2}+Z_{3}+Z_{4}
$$

where,

$$
Z_{1}=\frac{\pi^{4} D_{e}^{3} D \tan \theta_{p}}{2 h} \mu N^{2}
$$

$Z_{1}$ is for within the channel condition where $D$ is the barrel diameter (m); $h$ is the channel depth (m); $\mu$ is the Newtonian viscosity $\left(\mathrm{Ns} / \mathrm{m}^{2}\right) ; \theta$ is the screw helix angle.

$$
Z_{2}=\frac{\pi^{2} D^{2} e C_{e}}{\delta} m^{*} \mu N^{2}
$$

$Z_{2}$ is for the condition between the flight tip of the screw and the inside surface of the barrel where $e$ is the screw flight tip width in axial direction (m); $C_{e}$ is the equivalent twin screw circumference $(\mathrm{m}) ; \mathrm{m}^{*}$ is the number of screw flights

$$
Z_{3}=\frac{8 \pi^{2} I^{3} e}{\varepsilon} m^{*} \mu N^{2}
$$

$Z_{3}$ is for the condition between the flight tip of one screw and the bottom of the channel of the other screw where $I$ is the distance between screw shafts (m); $\varepsilon$ is the clearance between flight tip and channel bottom of two opposite screws (m)

$$
Z_{4}=\frac{\pi^{2} I^{2} h \sqrt{\left(D^{2}-I^{2}\right)}}{2 \sigma} m^{*} \mu N^{2}
$$

$Z_{4}$ is for the condition between the flights of opposite screws parallel to each other where $\sigma$ is the clearance between flights of opposite screws parallel to each other.

A heat balance across an element in the melt-pumping zone with the boundary condition $T=T_{m}^{0}$ at $X=X_{m}^{0}$ can be written as

$$
\frac{\partial T}{\partial X}=C_{2 P} \exp \left(-b_{1} T\right)+C_{3 p}\left(T_{b}-T\right)
$$

where,

$$
C_{2 P}=\frac{C_{1 P} \mu_{p} N^{2}}{\pi D \tan \varphi_{p} Q_{m} C_{p m}}
$$

and

$$
C_{3 p}=\frac{F A}{Q_{m} C_{p m}}
$$

where, $C_{p m}$ is the heat capacity of molten matter $(\mathrm{J} /(\mathrm{kg} \cdot \mathrm{K})) ; \quad b_{1}$ is the temperature coefficient of viscosity; subscript $m, p, b, 0$ are for melt material, pumping section, barrel and initial/reference condition respectively.

The mechanism of flow and heat generation in the melt shearing section (reverse element section) is extremely complicated. The existence of cross-channels normal to the screw channel adds to this complication. The temperature profile of this section is:

$$
\frac{d T}{d X}=\left(C_{2 r s}+C_{4 r s}\right) \exp \left(-b_{1} T\right)+C_{3 r s}\left(T_{b}-T\right)
$$

where, $C_{2 r s}$ and $C_{3 r s}$ are similar to $C_{2 p}$ and $C_{3 p}$ described in the melt pumping section. $\mathrm{C}_{4 \mathrm{rs}}$ can be calculated as:

$$
C_{4 r s}=\frac{Q_{m} D \mu_{r s} \dot{\gamma}_{r s}^{n_{1}}\left(\frac{1-m_{1} B G}{\pi D h}\right)}{C_{p m} h^{5} \tan \varphi_{p}}
$$

where, $n_{1}$ is the power-law index; $B$ is the width of reverse cross-section (m); $G$ is the depth of reverse cross-channel (m); a subscript $r$ is for reverse screw section. 
An improvement was made for the analysis presented above [29, 52]. In their theory, the solid was presented as a uniform layer of thickness $E$ (m), situated in the channel between screw tips.

The thickness of this layer was calculated assuming a constant angle of $\varphi$ (rad) determined by the feed rate, thus depending on the feed rate $Q(\mathrm{~kg} / \mathrm{h})$, screw rotation speed, $N$ (r/min) and the local screw geometry (pitch $\mathrm{B}(\mathrm{m})$, external radius $\mathrm{R}_{\mathrm{e}}(\mathrm{m})$, width of screw flight, l (m)). The energy balance equation is slightly different from Yacu's equation with the addition of a term accounting for the energy generated by the friction of the screw tip over the material located in the clearance between it and the barrel surface.

$$
\begin{gathered}
Q C_{P} \frac{d T}{d z}=\frac{k N u}{E}\left(T_{b i}-T\right) 2 \varphi R_{e}+ \\
f P R_{e} \frac{2 \varphi l}{B-l} \frac{2 \pi N}{60}
\end{gathered}
$$

where, $C_{p}$ is the specific heat of the material $\left(\mathrm{J} /\left(\mathrm{kg} \cdot{ }^{\circ} \mathrm{C}\right)\right) ; \mathrm{T}$ is the temperature $\left({ }^{\circ} \mathrm{C}\right) ; \mathrm{z}$ is the axial coordinate $(\mathrm{m}) ; P$ is the pressure created in the layer by the passage of the screw flight; $k$ is the thermal conductivity of the material $\left.\left(\mathrm{W} / \mathrm{m} \cdot{ }^{\circ} \mathrm{C}\right)\right) ; f$ is the metal-powder friction coefficient; $T_{b i}$ is the barrel surface temperature $\left({ }^{\circ} \mathrm{C}\right)$.

The model developed [53, 54] calculates the total transferred heat in the extruder for every position on the screw axis. The model consists of two parts. The first part calculates the heat penetration from the barrel to the extrudate and the second part calculates the heat generated by viscous dissipation. The model has now been improved [55] such that it is suitable for calculation with the aid of a computer.

Several authors have worked on melt flow analysis for Newtonian, isothermal flow condition and non-Newtonian rheological behavior [12, 42, 44]. No direct measurement of shear in an extruder has ever been reported [37]. The effect of shear is to increase product temperature by heat generation due to highly viscous nature of extruded products. The shear rate is calculated as the ratio of the screw tip velocity to the channel or clearance depth.

A model was presented for estimating the average shear rate in corotating twin-screw extruder [56]. Newtonian and non-Newtonian fluids were used to estimate the average shear rate for three screw configurations of Baker Perkins (MPF-500) twin-screw extruder section with a range of screw speed (100-400 r/min). The changes in temperature have been verified using various screw profiles [57].

In an attempt to improve on flow and heat modeling studies, a study was carried out on 2D flow simulation in food extruder die for intermeshing co-rotating twin-screw extruder [6]. This study used finite element computer package ANSYS/FLOTRAN and the results obtained showed that the values obtained for die exit temperature by simulation procedure and by experiments compared favorably.

\section{Extrusion Processing Parameters and Product Quality}

A proper understanding of how processing parameters affect the thermo-mechanical, rheological and structural transformation of food polymers into final product will enhance the development of extrusion cooking technology. The early studies of the extrusion processing of food material mainly focused on the effects of physico-chemical parameters of temperature and extrusion moisture content on product properties [58]. The product properties studied then were color, expansion ratio, bulk density and the viscosity of dilute aqueous dispersion.

Later studies show the importance of process variables that control the mechanical history and residence time of materials such as screw speed, feed rate and die geometry [59]. Influence of extrusion cooking conditions on the product qualities have been generally studied and modeled. The expansion and the shear strength of the products are highly dependent on extrusion cooking conditions. Extruder barrel temperature affected the expansion of corn grits and cornstarch, potato starch and corn germ flour [60]. 
Lower moisture contents favored the expansion of materials such as corn grit, cornstarch, wheat flour and germ flour [60].

A relationship had been developed between viscoelastic properties of melted starch and its expansion volume. It has also been noted that extrusion pressure and die-nozzle length-to-diameter ratio greatly affected the expansion of cornstarch. Among other extrusion processes studied which affect expansion volume of extrudate are degree of gelatinization, amylase content and apparent viscosity [61].

Effects of screw speed, feed moisture, feed rate and product temperature on two procession efficiency variables (percent torque and specific energy input) and product quality (density ratio, hardness ratio and color) have been studied [62]. Increased product temperature or feed moisture decreased both the specific energy input and percent torque. A higher screw speed decreased percent torque but increased specific energy input and vice versa for the increase in the feed rate.

Mathematical modeling of the effects of extrusion processing parameters on extrudate is becoming more popular for scale up purposes. Bhattacharya [63] proposed mathematical model to predict the rheological properties of dough. The properties are consistency coefficient, flow behavior index and apparent viscosity of blends during extrusion. A simple mathematical model was developed to predict different rheological properties of the dough using data from a tube viscometer.

Since most die geometry have circular cross-section, the Newtonian fluid flow through a tube of radius, $r_{c}$ and a pressure drop, $\Delta P$ occurs over the conduit length, $L_{T}$, then the shear stress, $\tau_{w}$ at the wall of the conduit is given by:

$$
\tau_{w}=\frac{\Delta P \pi r_{c}^{2}}{2 \pi r_{c} L_{T}}=\frac{\Delta \operatorname{Pr}_{c}}{2 L_{T}}
$$

where, $r_{c}$ is the radius of the conduit (mm).
For a Newtonian fluid, with laminar and isothermal condition, the viscosity, $\mu$ is given by the Hagen-Poiseuille law,

$$
\mu=\frac{\Delta \operatorname{Pr}_{c}^{2}}{8 L_{T} \bar{V}}
$$

where, $\bar{V}$ is the average velocity of the fluid through the pipe $\left(\mathrm{mms}^{-1}\right)$.

If $\dot{\gamma}_{w n}$ is the shear rate for the Newtonian fluid at the walls of the tube,

$$
\mu=\frac{\tau_{w}}{\dot{\gamma}_{w n}}
$$

Substituting the value of $\tau_{w}$ in Eq. (26) gives

$$
\mu=\frac{\Delta \operatorname{Pr}_{c}}{2 L_{T} \dot{\gamma}_{w n}}
$$

Eqs. (27) and (29) yields

$$
\dot{\gamma}_{w n}=\frac{4 \bar{V}}{r_{c}}
$$

For non-Newtonian power law fluid, the wall shear rate is

$$
\dot{\gamma}_{w}=\frac{3 n+1}{4 n} \frac{4 \bar{V}}{r_{c}}
$$

where, $n$ is the dimensionless flow behavior index. The factor $(3 n+1) / 4$ is called the wall shear rate correction factor. The shear stress at the wall of the tube is

$$
\tau_{w}=k\left(\dot{\gamma}_{w}\right)^{n}
$$

Since the shear rate for a power law fluid is

$$
\tau=k(\dot{\gamma})^{n}
$$

where, $k$ is the consistency index.

Putting the values of $\tau_{w}$ and $\dot{\gamma}_{w}$ from Eqs. (26) and (31) respectively, into Eq. (32) and taking the logarithm of both sides

$$
\lg \frac{\Delta \mathrm{Pr}_{c}}{2 L_{T}}=\log \left[k\left(\frac{3 n+1}{4 n}\right)^{n}\right]+n \lg \frac{4 \bar{V}}{r_{c}}
$$


The apparent viscosity at the barrel wall in the metering section of the screw is given by

$$
\mu_{s}=k\left(\dot{\gamma}_{s}\right)^{n-1}
$$

Assuming that the extruder is a closely spaced coaxial rotating cylinder, the apparent shear rate, $\dot{\gamma}_{s}$ in the screw is:

$$
\dot{\gamma}_{s}=\frac{\pi D N}{H}
$$

where, $D$ is the internal diameter of the extruder barrel (mm), $N$ is the rotational speed of the extruder screw ( $\mathrm{r} / \mathrm{min}), H$ is the gap between the inside of the barrel and root of the screw in the metering section (mm).

The apparent viscosity at the die $\mu_{d}$ would be:

$$
\mu_{d}=k\left(\dot{\gamma}_{d}\right)^{n-1}
$$

where, $\dot{\gamma}_{d}$ is the apparent shear rate at the die (s).

From Eq. (31),

$$
\chi=1-\left\{1-\exp \left[-k_{0} \exp \left(\frac{-\left(\Delta E_{0}-\beta \tau\right)}{(R T)}\right) t\right]\{1-\exp (-k \tau t+B)\}\right.
$$

where, $\tau$ is the average shear stress, $t$ is the mean residence time of the melt in the active zone of the screw channel, $\Delta E_{0}$ is the activation energy, $R$ is the ideal gas constant, $\beta$ is the activation volume, $k$ and $k_{0}$ are experimental constants.

In the work on predictive equations and response surface analysis for grain sorghum [6], the extrusion and extrudate properties measured include expansion indices (or puff indices), bulk density, residence time, solid density, moisture content, maximum stress, water solubility index (WSI), water absorption index (WAI), extruder output, crispness and color.

The ranges of the three variables considered were $100-160{ }^{\circ} \mathrm{C}$ for barrel temperature, $100-200 \mathrm{r} / \mathrm{min}$ for screw speed, and $15 \%-25 \%$ for feed moisture content (w.b.). The density of extrudate measured varied between 176 and $1,100 \mathrm{~kg} / \mathrm{m}^{3}$ for the extrusion variables considered. The moisture content of the dry extrudate is between $6 \%$ and $7.5 \%$.

From the experimental results, predictive equations

$$
\dot{\gamma}_{d}=\frac{4 \bar{V}_{d}}{r_{d}} \frac{3 n+1}{4 n}
$$

where, $r_{d}$ is the radius of the die $(\mathrm{mm})$ and $\bar{V}_{d}$ is the average velocity of the fluid at the die $(\mathrm{mm} / \mathrm{s})$. Assuming that the power law constants, $n$ of the feed is constant at the die and the screw channel, their apparent viscosity ratio $\mu_{d} / \mu_{s}$ compares favorably (is almost the same).

An adaptation of the first order mechano-degradation models was made for single screw extruder to twin screw extruder [64]. They processed wheat starch in a co-rotating twin-screw extruder at moisture contents of $25 \%$ and $30 \%$, screw speed of $200 \mathrm{r} / \mathrm{min}$ and $300 \mathrm{r} / \mathrm{min}$, feed rate of $30 \mathrm{~kg} / \mathrm{h}$ and barrel temperature settings of 100, 120, 140 and $160{ }^{\circ} \mathrm{C}$. The developed equation for degradation is: were developed to relate the influence of processing parameters on the grain sorghum extrudate quality. Using Matlab computer software for the response surface diagram (RSD), it was discovered that the effect of screw speed on density is negligible. Temperature has a significant impart on the density of the extrudate and it has a curvilinear effect on extrudate density and at high temperature, its quadratic effect dominates. Specific Mechanical Energy (SME) is directly proportional to screw speed. Comparatively, the screw speed has dominating effects on SME while temperature had a small effect.

The results of the taste panel on crispness and color show that the product extruded at the conditioned feed moisture content of $20 \%$ and barrel temperature of $150{ }^{\circ} \mathrm{C}$ gave the best crispness and color quality.

There is the need for fundamental studies on the properties of food just as in plastic extrusion. Understanding the properties of food dough will help in obtaining information on thermo-mechanical 
properties and flow properties of food dough. These properties are useful in engineering design, analysis and extruder scale up.

As the technology of food extrusion is getting more developed, many researchers are diversifying into the area of food formulation. In our ever-changing consumer demands, there is the need for concerted effort to provide consumer with new and improved products. Food scientists and technologists are taking up this challenge by using additives or co-extrusion techniques to produce foods of higher nutritional quality.

However, the addition of food ingredients such as sugar, salt may significantly affect the extrusion processing parameters, product taste and product qualities such as bulk density [65]. The effect of screw speed and additive (sugar and salt) on processing and product variables of corn meal extruded with a twin-screw extruder has been reported [66]. Higher salt (0-3\%) and sugar concentrations (0-4\%) in the feed decreased the die pressure, percentage torque and specific energy. At $6 \%$ and $8 \%$ sugar, higher screw speed (200-250 r/min) decreased die pressure and percentage torque but increased specific energy. The addition of salt and sugar enhanced extrudate radial and axial expansions. An increase in screw speed decreased radial expansion and bulk density, but increased axial expansion and breaking strength.

Similar food formulation extrusion experiment was recently performed using BC45 corotating twin-screw extruder [67]. In the experiment, it was reported that corn snack is best produced at $160^{\circ} \mathrm{C}$ die temperature, $150 \mathrm{r} / \mathrm{min}$ screw speed with feed composition of corn flour (69.6\%), rice flour (17.4\%), sugar (4\%) and salt (1\%).

Some works were also carried out on co-extrusion of food materials to form a composite extrudate. A twin-screw extruder was used to texturize a co-precipitated concentrate of soybean and peanut proteins, prepared from flours along with two soy-peanut concentrate blend followed by rheological, functional and ultrastructural analysis of the texturized products [68]. Twin-screw texturization of co-precipitated soy-bean and peanut proteins produced a highly moist, less structurally rigid and moderately expanded products compared to individually textured soybean and peanut protein concentrates.

Blends of corn gluten meal and soy protein concentrate in the ratio of $25: 75,50: 50$ and $75: 25$ (moisture contents of $20 \%, 30 \%$ and $40 \%$ d.b.) were extruded at $145{ }^{\circ} \mathrm{C}$ through 4.24, 3.0 and $2.12 \mathrm{~mm}$ diameter die [69]. The influence of ingredient (bran, sucrose and magnesium carbonate) on extrusion cooking of wheat flour was also studied [70]. An increase in apparent density occurred when concentration of any of the ingredient increased. Cell number per pixel area increased greatly while average cell size decreased as bran concentration increased from 0 to $16 \%$. Average cell size increased as magnesium carbonate increased from 0 to $0.4 \%$ but cell size decreased above $0.4 \%$.

Extrusion cooking have also been used for high moisture food [71] such as deboned chicken meat (60\%-65\% water, 20\%-22\% lipid, 15\%-17\% protein) and soybean protein isolate (SPI) under high moisture over $70 \%$ water $\mathrm{w} / \mathrm{w}$ [72]. A methodology was developed for examining bacterial spore destruction during extrusion cooking and determination of the effect of various extrusion parameters on destruction of spores of Bacillus globigii in corn/soybean mixture [73].

There are many studies related to the effects of process parameters on extrusion efficiency as highlighted in this paper. The studied process parameters are so varied in such a way that it might be impossible to exhaustively review them in a single paper. The conclusions from the studies varied widely and sometimes confusing. Even with almost the same process conditions, the results obtained are quite different and incoherent. Inadequate optimization studies are carried out to confirm the obtained experimental optimum process parameter values. The 
reasons for these discrepancies may be due to the differences in experimental conditions, types and conditions of the extruder used, measuring techniques and equipment used. Other reasons may be instability of studied parameter values, method of result analysis and the objective of the study, which places constraints on the level of experimental accuracy needed.

There is no standardized experimental procedure and method of analysis for food extrusion technology as available for other conventional food processing techniques. So every study tends to use the method adaptable to its own peculiar condition. Works on mechanical and rheological properties of food dough are urgently required. It is understandable that this is a big research projects since there are hundreds of food dough that may be suitable for extrusion process, but serious research works need to be initiated.

However, it is worth noting that the works so far reported can form a good basis for further improvement and studies. Available data need to be collected, collated and analyzed to come out with acceptable usable information not only for research purposes but also for commercial production.

From the foregoing, it is obvious that a lot of work had been carried out on the influence of extrusion process parameters on extrudate quality. Present focus should now be in the area of co-extrusion of cereals and additives. This is indeed a promising area for developing countries which are rich in cereal used as traditional food products. Such improvements will enhance the nutritional quality of these traditional foods and provide the populace with value-added foods. This could be a potential source of huge economic benefits to food processors.

\section{Extruder Die and Product Expansion}

The die is a major component of the extruder set up. The die allows rapid expansion "puffing" of the dough into various shapes and sizes depending on the configuration of the die section. Understanding material properties and nature of flow in the extruder die is of primary importance in controlling the extruder performance and product quality.

The pressure drop at the die entrance for a visco-elastic fluid has been observed to be far greater than the entrance pressure for a Newtonian fluid of nearly the same viscosity. Entrance pressure drop of extruder dies increased with a decrease in the ratio of barrel to die diameter during the extrusion of corn. Entrance pressure drop affects barrel to die diameter ratio, flow within the die and shear stress among others. These factors are reported to be very important in the design of food extruder die [4].

In this work, two types of die designs were presented. The designed dies were produced, mounted on food extruder and used for several experiments. Some of the die design considerations and extrusion process optimization parameters employed include: the throughput of the extruder, desired shape, size and uniformity of the extrudate, the relationship between the flow and pressure drop in the die and the relationship between shear rate and viscosity of the food dough. Specific die design considerations also include: die nozzle dimensions such as diameter and length, and number of die hole, ratio of die length to diameter (L/D ratio) and flow, deformation and temperature relationship.

This will be the first time that a systematic design work on dies for food extruder is being carried out and reported. The designed dies in this work will be able to handle food dough mostly cereal flours, the die nozzles are circular, nozzles diameters range from 2.5-5 mm and nozzle lengths range from $14-90 \mathrm{~mm}$. The dies are designed for twin-screw extruder screw diameter of 50-60 mm, extruder output of 30-50 kg/h and 100-300 $\mathrm{r} / \mathrm{min}$ screw speeds. The dies were able to withstand temperature of $250{ }^{\circ} \mathrm{C}$ and up to $12 \mathrm{MPa}$ of pressure as frequently experienced in food. The expansion volume of starch is mainly dependent on its degree of gelatinization within the extruder.

Die nozzle diameter and length play a very 
important role in starch extrusion expansion. The backpressure in the extruder barrel is directly proportional to the nozzle L/D ratio. Until recently there was no reported work on the effect of die parameters on extruder performance for twin screw extruder despite the wider usage of twin screw extruder over single-screw extruder. Most of the works on the effect of die dimensions on extruder performance where available are on single-screw extruder.

The process conditions in combination with die parameters may also have significant effects on extruder performance. When dough enters a die from an extruder barrel, a velocity profile starts to develop and continues to change until it reaches a specific distance beyond which flow is fully developed. The flow of extrudate through the opening could be likened to fluid flow through an enclosed pipe under pressure. It is likely that the basic formulae of fluid dynamics can be used to model the flow through the die.

There exists the basic relationship between the characteristics of the design, flow and pressure drop in literature. The pressure drop at the die entrance for a viscoelastic fluid has been observed to be far greater than the entrance pressure for a Newtonian fluid of nearly the same viscosity [74]. The reason for the large entrance pressure may be attributed to the elastic component of the viscoelastic fluid.

Entrance pressure drop of extruder dies increased with a decrease in the ratio of barrel to die diameter during the extrusion of corn. Entrance pressure drop affects barrel to die diameter ratio, flow within the die and shear stress among others. These factors are important in the design of food extruder, which is one of the areas of study in the present work. The expansion volume of starch is mainly dependent on its degree of gelatinization within the extruder [75].

Die nozzle diameter and length play a very important role in starch extrusion expansion. In an experiment with single-screw extruder, an optimum extrusion pressure was obtained for the best expansion of $14 \%$ moisture starch with a nozzle having an L/D ratio of 3.4 [6]. The back pressure in the extruder barrel is directly proportional to the nozzle $\mathrm{L} / \mathrm{D}$ ratios.

A recent study was carried out to determine the effects of die dimensions on extruder performance [76]. Yellow corn grits having 18\% moisture content (d.b.) were extrusion cooked in a single-screw laboratory extruder at $140{ }^{\circ} \mathrm{C}$ barrel temperature and $140 \mathrm{r} / \mathrm{min}$ screw speed. The nozzle diameter ranged from $2 \mathrm{~mm}$ to $6.2 \mathrm{~mm}$ and the die nozzle lengths ranged from $5.48 \mathrm{~mm}$ to $50.3 \mathrm{~mm}$. The study concluded that die diameter affected the radial expansion of the extrudate. Axial and overall expansions were not affected by die diameter.

In the light of this, a recent study was carried out to determine the effects of food extruder die dimensions on the extrudate expansion indices using twin-screw extruder [8]. The extruder has $59.6 \mathrm{~mm}$ screw diameter and screw L/D ratio of 20. The die dimensions considered are die length, die diameter and die temperature. The feed material used is yellow corn flour. Dies with diameter ranging from 2.5-5.0 $\mathrm{mm}$ were used to determine the effect of die nozzle diameter on extrudate expansion.

Results obtained showed that radial expansion of the extrudate decreased with increasing die diameter. The regression model shows that SME decreased with increasing die diameter. Dies with length ranging from 16-54 mm with a constant nozzle diameter of $3 \mathrm{~mm}$ were used to determine the effects of die nozzle length on extrudate expansion. The die length significantly influenced axial expansion of extrudate. Axial expansion increased with increase in die length.

A linear regression model was developed to relate die length to extruder SME. The quadratic effect is negligible in this case and as such was not included in the regression equation. Effects of die nozzle L/D on radial expansion of extrudate during extrusion were also studied. Experimental results on the effects of die diameter and die length on flow characteristics 
revealed that when all other extruder conditions are kept constant, increasing the diameter of the die nozzle causes increase in the volumetric flow rate of extrudate. Flow rate decreases proportionally with increasing die length.

Normally, in extrusion cooking a reduction in the size of die aperture causes an increase in die resistance and therefore an increase in die pressure. The role of die in defining texture in extruded products is often overlooked and underestimated. Die shape will influence finished piece shape and texture. Tapered die hole will reduce backpressure requirements, create a smoother product surface and cause less mechanical damage to the extruded ingredients. A die insert having an abrupt cross-sectional change and short land length will cause greater mechanical damage to food ingredients and lead to finer cell structure.

The laminar-flow shear environment through the die affects texture and can be characterized by the shear rate. Dies having a higher shear rate have a potentially greater effect on product texture. High shear rates at the die cause greater shear-induced damage and reduces molecular size, creating softer-textured products with smaller pores, increased solubility and less mechanical strength. The die can also extensively influence the textured soy protein.

\section{Conclusion}

Food extrusion is a technology that will continue to receive research and application attention in developed and developing countries. It is practically impossible to discuss in details every aspects of food extrusion technology in this single paper. However, the paper focused on relevant theories, research efforts and application of the technology.

The potentials and benefits of the technology is immense and yet to be tapped fully. In particular, food industries in developing countries have a lot of benefits from research and application of this technology. Serious research efforts are needed in developing countries to increase awareness on the application potentials of this technology. New food products can be produced from the abundant available cereals. Developing countries cannot afford to be left behind in utilization of this modern food processing technique.

There is no standardized experimental procedure and method of analysis for food extrusion technology as available for other conventional food processing techniques. Studies of mechanical and rheological properties of food dough are urgently needed. There is the need for fundamental studies on the properties of food just as in plastic extrusion where properties of plastics and plastic melt are well known. Understanding the properties of food dough will help in getting information and data for research and development purposes.

Focus should also be in the area of co-extrusion of cereal products with other additives. This is a promising area for developing countries which are rich in cereal. At present, these cereals are grossly underutilized in terms of processing. Improvement in processing as being offered by extrusion cooking will enhance nutritional quality of these foods and provide the populace with value-added foods. This is a potential source of huge economic benefits and research opportunities.

\section{References}

[1] Tadmor, Z., and Klein, I. 1970. "Engineering Principles of Plasticating Extrusion.” Polymer Engineering and Science 10 (1): 55-67.

[2] Kolani, J. L. 1993. “The Effect of Processing History on Chemical Changes in Single-Screw and Twin-Screw Extruders.” Trends in Food Science and Technology 4 (10): 324-9.

[3] Harper, J. M. 1986. "Extrusion Texturization of Foods.” Food Technology 6 (3): 70-6.

[4] Adekola, K. A. 2014. "Analytical Engineering Designs for Twin-Screw Food Extruder Dies.” International Journal of Engineering Innovation and Research 3 (5): 713-7.

[5] Wiedman, W., and Strobel, E. 1987. "Processing and Economic Advantages of Extrusion Cooking in Comparism with Conventional Processes in Food Industry." Extrusion Technology for the Food Industry, 
edited by O'Connor, W. Netherlands: Elsevier Science, 132-69.

[6] Adekola, K. A. 1999. Studies into Twin-Screw Food Extruder Die. Changchun, PhD thesis, Jilin University, China.

[7] Adekola, K. A., Ma, C. L., and Zuo, C. C. 1998. "Estimation of Temperature Profile in Food Extruder Dies." Transactions of the Chinese Society of Agricultural Engineering 14 (3): 226-30.

[8] Adekola, K. A. 2015. "Influence of Food Extruder Die Dimensions on Extruded Products Expansion.” Agricultural Engineering International: CIGR Journal 17 (1): 255-63.

[9] Gray, M. 1879. British Patent. 5056.

[10] Royle, V., and Rooyle Jr., R. 1885. U.S. Patent. 325360.

[11] Pfleiderer, P. 1881. U.S. Patent. 18797.

[12] Yacu, W. A. 1984. "Modeling of a Twin-Screw Extruder." In Conference on Thermal Processing and Quality of Foods, Athen, Greece, 55-60.

[13] Adekola, K. A. 2015. "Two Dimensional Flow Simulation in Intermeshing Co-Rotating Twin-Screw Corn Extruder Die.” Agricultural Engineering International: CIGR Journal 17 (3): 263-77.

[14] Rauwendaal, C. 1986. "The ABC of Extruder Screw Design.” Advances in Polymer Technology 9 (4): 301-8.

[15] Rossen, J. L., and Miller, R. C. 1973. "Food Extrusion.” Food Technology (Chicago) 27 (8): 46-58.

[16] Miller, B. C. 1984. "Effect of Wears on Twin-Screw Extruder Performance.” Food Technology 2 (1): 10-4.

[17] Tadmor, Z., and Klein, I. 1969. "The Effect of Design and Operating Conditions on Melting in Plasticating Extruders.” Polymer Engineering and Science 9 (1): 11-7.

[18] Fenner, R. T. 1970. Extruder Screw Design. 1st. ed, London: lllife Books, 25-67.

[19] Wyman, C. E. 1975. “Theoretical Method for Intermeshing Twin-Screw Extruders: Axial Velocity Profile for Shallow Channels.” Polymer Engineering and Science 15 (8): 59-68.

[20] Eise, K., Jakopin, H., Herrman, H., and Burkhardt, U. 1981. "An Analysis of Twin-Screw Extruder Mechanisms." Advances in Plastic Technology 1 (2): 12-8.

[21] Chella, R., and Ottino, J. M. 1985. "Fluid Mechanics of Mixing in a Single-Screw Extruder.” Industrial Engineering and Chemicals Fundamentals 24 (5): 170-8.

[22] Frickle, A. L., Charke, J. P., and Mason, T. F. 1977. "Cooking and Drying of Fortified Cereal Foods: Extruder Design.” Chemical Engineering Journal 73 (6): 134-45.

[23] Tayeb, J., Della Valle, G., Barres, C., and Vergnes, B. 1991. "Simulation of Transport Phenomena in Twin-Screw Extruders.” Journal of Food Science 56 (8): 962-9.
[24] Burkhardt, K., Hermann, H., and Jakopin, S. 1978. "Food Extrusion Process and Equipment.” SPE ANTEC Technical Papers 24 (1): 35-51.

[25] Booy, M. L. 1980. "Geometry of Fully Wiped Twin Screw Equipment (II).” Polymer Engineering and Science 20 (12): 1220-6.

[26] Stevens, M. J. 1985. "Extruder Principles and Operation.” Food Technology 36 (3): 67-80.

[27] Eise, K., Curry, J., and Nangeroni, J. F. 1983. "Compounding Extruders for Improved Polybends." Polymer Engineering and Science 23 (8): 642-6.

[28] Ainsworth, P., Ibanoglu, S., and Hayes, G. D. 1997. "Influence of Process Variable on Residence Time Distribution and Flow Pattern of Tarhana in a Twin-Screw Extruder.” Journal of Food Engineering 32 (1): 101-8.

[29] Tayeb, J., Vergnes, B., and Della Valle, G. 1989. “A Basic Model for a Twin-Screw Extruder.” Journal of Food Science 54 (9): 1047-56.

[30] Booy, M. L. 1978. "Geometry of Fully Wiped Twin Screw Equipment.” Polymer Engineering and Science 18 (9): 973-80.

[31] Kim, M. H., and White, J. L. 1989. "Simulation of Flow in Modular Tangential Counter-Rotating Twin-Screw Extruders: Screw Flight Staggering and Backward Pumping Elements.” SPE ANTEC Technical Paper 35 (2): 49-60.

[32] Ollet, A. L., Li, Y., Parker, R., and Smith, A. C. 1989. “A Comparative Study of the Conveying Performance of Screw in a Twin-Screw Co-Rotating Extrusion Cooker.” Journal of Food Engineering 10 (3): 165-81.

[33] Yang, H. H., and Manas-Zloczower, I. 1992. "Flow Profile in Kneading Elements in the Intermeshing Corotating Twin-Screw Extruder.” Polymer Engineering and Science 32 (7): 1411-20.

[34] Van Der Wal, D. J., Goffart, D., Klomp, E. M., Hoogstraten, H. W., and Janseen, P. B. M. 1996. "Three-dimensional Flow Modeling of a Self-Wiping Corotating Twin-Screw Extruder. Part II: The Kneading Section.” Polymer Engineering and Science 36 (7): 912-24.

[35] Goffart, D., Van Der Wal, D. J., Klomp, E. M., Hoogstraten, H. W., Janseen, L. P. B. M., Breysse, L., and Trolez, Y. 1996. "Three-dimensional Flow Modeling of a Self-Wiping Corotating Twin-Screw Extruder. Part 1: The Transporting Section.” Polymer Engineering Science 36 (7): 901-11.

[36] Martin, B., Pearson, J. R. A., and Yates, B. 1969. Numerical Studies of Steady State Extrusion Process. Polymer Research Center Report of Cambridge University Department of Chemical Engineering, UK.

[37] Tayeb, J., Della Valle, G., Barres, C., and Vergnes, B. 
1990. "Simulation of Transport Phenomena in Twin-Screw Extruders.” Journal of Food Science 56 (8): 990-8.

[38] Harmann, D. V., and Harper, J. M. 1973. "Effects of Extruder Geometry on Torque and Flow.” Transactions of the ASAE 16 (6): 1175-8.

[39] Vergnes, B. 1997. Analysis and Modeling of the Twin-Screw Extrusion Process. Report on 40 years of Twin-Screw Extrusion at Clextral, France.

[40] Janseen, L. B. P. M. 1986. "Models for Cooking Extrusion.” Food Engineering and Process Applications, edited by Le Maguer, M., and Jelen, P. London: Elsevier, 115-29.

[41] Pearson, J. R. A. 1966. "Mechanical Principles of Polymer Melt Processing." Transactions of Society of Rheology 13 (3): 357-9.

[42] Yankov, V. I. 1984. "Hydrodynamic and Hest Transfer of Apparatus for Continuous High-Speed Production of Polymer Solutions." Heat Transfer Soviet Research 10 (3): 67-71.

[43] Anders, S., Brunner, D., and Jacob, P. 1980. "Rechen program zur simulation des plastizier prozesses beim einschneckenextruder. "Plaste kautsch 12 (6): 687-93.

[44] Bruker, I. 1987. "Numerical Analysis of the Temperature Profile in the Melt Conveying Section of a Single-Screw Extruder in Comparism with Experimental Data.” Polymer Engineering and Science 27 (7): 504-9.

[45] Maddock, B. H. 1959. "Technical Analysis of Plastic Extrusion.” Society of Plastics Engineering Journal 15 (2): 383-8.

[46] Harper, J. M. 1981. Extrusion of Foods, 2nd ed. London: CRC Press, 101-55.

[47] Todd, D. B. 1988. "Heat Transfer for Viscous Material in a Corotating Intermeshing Twin-Screw Mixer.” In 6th European Conference on Mixing, Pavia, Italy, 533-6.

[48] Jepson, O. H. 1953. "Future Extrusion Studies." Industrial Chemical Engineering 45 (11): 992-1000.

[49] Martelli, F. 1983. Twin-Screw Extruder-A Basic Understanding, 1st ed. London: Van Nostrand, 1-28.

[50] Mohammed, I. O., Morgan, R. G., and Ofoli, R. Y. 1988. "Average Convective Heat Transfer Coefficient in Single Screw Extrusion of Non-Newtonian Food Material.” Biotechnology Progress 4 (2): 68-75.

[51] Van Zuilichem, D. J., Lamers, J., and Kuiper, L. 1990. "The Development of a Heat Transfer Model for Twin-Screw Extruders.” Journal of Food Engineering 11 (3): 187-207.

[52] Tayeb, J. 1986. Approche Theorique et Experimentale de la Cuisson-Extrusion de L'amidon. Paris, France: Ecole des Mines de Paris, PhD thesis.

[53] Van Zuilichem, D. J., Alblas, B., Reinders, P. M., and Stolp, W. 1983. “A Comparative Study of the Operational
Characteristics of Single and Twin-Screws Extruders.” In Thermal Processing and Quality of Foods, edited by Zeuther, P., Cheftel, J. C., and Eriksson, C. Netherlands: Elsevier Science, 46-66.

[54] Van Zuilichem, D. J., Tempel, W. J., Stolp, W., and Van’t Riet, K. 1985. "Production of High-Boiled Sugar Confectionery by Extrusion-Cooking of Sucrose: Liquid Glucose Mixtures.” Journal of Food Engineering 4 (1): 37-51.

[55] Van Zuilichem, D. J., Jager, T., Spaans, E., and De Ruigh, P. 1989. "The Influence of a Barrel Valve on the Degree of Fill in A Corotating Twin-Screw Extruder.” Journal of Food Engineering 10 (4): 241-54.

[56] Mohammed, I. O., Ofoli, R. Y., and Morgan, R. G. 1990. "Modeling the Average Shear Rate in a Corotating Twin-Screw Extruder." Journal of Food Process Engineering 12 (4): 227-46.

[57] Meuser, F., Van Lengerich, B., Pfaller, W., and Harmuth-Hoene, A. E. 1985. "The Influence of HTST Extrusion Cooking on the Protein Nutritional Value of Cereal Based Products.” Journal of Food Science 55 (8): 265-74.

[58] Anderson, R. N., Conway, H. E., and Peplinski, A. J. 1970. "Gelatinization of Corn Grits by Roll Cooking, Extrusion Cooking and Steaming." Starke 22 (2): 130-5.

[59] Van Zuilichem, D. J., Lamers, J., and Stolp. W. 1975. "Influence of Process Variables on the Quality of Extruded Maize." In Proceeding of 6th European Symposium on Engineering and Food Quality, Cambridge, UK, 213-40.

[60] Peri, C., Barbieri, R., and Casiraghi, E. M. 1983. "Physical, Chemical and Nutritional Qualities of Extruded Corn Germ Flour and Milk Blend.” Journal of Food Technology 18 (2): 43-51.

[61] Chinnaswamy, R., and Hanna, M. A. 1990. "Relationship between Viscosity and Expansion Properties of Variously Extrusion-Cooked Corn Grain Components.” Food Hydrocolloids 3 (5): 423-34.

[62] Hseih, F., Peng, I. C., and Huff, H. E. 1990. "Effects of Salt, Sugar and Screw Speed on Processing and Product Variables of Corn Meal Extruded with Twin-Screw Extruder.” Journal of Food Science 55 (1): 224-7.

[63] Bhattacharya, S., Das, H., and Bose, A. N. 1992. "Rheological Behavior during Extrusion of Blends of Minced Fish and Wheat Flour." Journal of Food Engineering 15 (2): 123-37.

[64] Cai, W., Diosady, L. L., and Rubin, L. J. 1995. "Degradation of Wheat Starch in a Twin-Screw Extruder.” Journal of Food Engineering 26 (3): 289-300.

[65] Hseih, F. 1988. Coextrusion of Corn Meal. Report of Department of Agricultural Engineering and Food 
Science and Nutrition, Univ. of Missouri, Columbia, MO., USA.

[66] Hseih, F., Huff, H. E., and Peng, I. C. 1990. "Studies of Whole Cottonseed Processing with a Twin-Screw Extruder.” Journal of Food Engineering 12 (4): 293-306.

[67] Zuo, C. C., Ma, C. L., and Zhang, S. Q. 2000. "Study on the Cooking Extrusion Conditions and Formula of Corn Snack by a Twin-Screw Extruder (in Chinese)." Transactions of the Chinese Society of Agricultural Engineers 16 (3): 91-3.

[68] Hagan, R. C., Dahl, S. R., and Villota, R. 1986. "Texturization of Co-Precipitated Soybean and Peanut Proteins by Twin-Screw Extrusion.” Journal of Food Science 51 (2): 367-70.

[69] Bhattacharya, M., Hanna, M. A., and Kaufman, R. E. 1986. "Textural Properties of Extruded Plant Protein Blends.” Journal of Food Science 51 (4): 988-93.

[70] Moore, D., Sanei, A., Van Hecke, E., and Bouvier, J. M. 1990. "Effect of Ingredients on Physical/Structural Properties of Extrudates.” Journal of Food Science 55 (5):
1383-7.

[71] Megard, D., Kitabatake, N., and Cheftel, J. C. 1985. "Continuous Restructuring of Mechanically Deboned Chicken Meat by HTST Extrusion Cooking.” Journal of Food Science 50 (12): 1364-9.

[72] Kitabatake, N., Megard, D., and Cheftel, J. C. 1985. "Continuous Gel Formation by HTST Extrusion Cooking: Soy Proteins.” Journal of Food Science 50 (12): 1260-5.

[73] Likimani, T. A., Sofos, J. N., Maga, J. A., and Harper, J. M. 1990. "Methodology to Determine Destruction of Bacterial Spores during Extrusion Cooking." Journal of Food Science 55 (5): 1388-93.

[74] Han, C. D. 1976. Rheology in Polymer Processing. 2nd edn., London: Academic Press, 19-88.

[75] Stanley, D. W. 1986. "Chemical and Structural Determinants of Texture of Fabricated Foods." Food Technology 40 (2): 65-72.

[76] Sokhey, A. S., Ali, Y., and Hanna, M. A. 1997. "Effects of Die Dimensions on Extruder Performance.” Journal of Food Engineering 31 (2): 251-61. 